\title{
Awake GlideScope®-assisted foreign body retrieval
}

\author{
Mark M. Smith, MD · Timothy Murray, MD - Adam W. Amundson, MD
}

Received: 30 August 2017/Revised: 12 September 2017/ Accepted: 27 September 2017/Published online: 10 October 2017

(C) Canadian Anesthesiologists' Society 2017

\begin{abstract}
A 38-yr-old woman with a history of repeated, intentional, foreign body ingestion presented after swallowing a disposable spoon. Initial attempts of esophagogastroduodenoscopy-assisted removal of the spoon from the gastric body under light sedation and topical viscous lidocaine failed. At this point, the foreign body had become lodged in the upper esophagus, causing intermittent, nearly complete laryngeal obstruction (Figure A). The procedure was aborted and following a transient period of respiratory distress, unassisted spontaneous ventilation with stable respiratory parameters resumed. The patient was transferred to the operating room where nasopharyngeal examination confirmed that the foreign body remained near the larynx in the upper esophagus. After local anesthetic airway topicalization with $20 \%$ benzocaine aerosolized spray and $4 \%$ lidocaine via syringe atomizer, a GlideScope ${ }^{\circledR}$ video laryngoscope (\#3 blade; Verathon Inc., Bothell, WA, USA) was cautiously inserted into the oropharynx allowing visualization of the spoon (Figure B). With the concern of not being able to pass an endotracheal tube successfully around the foreign body, and continued stable respiratory status, the decision was made to pursue awake foreign body retrieval. The anesthesiologist used the GlideScope ${ }^{\circledR}$ to visualize and guide the otorhinolaryngologist's insertion of a rigid bronchoscopic grasping forceps to retrieve the foreign body (Figure C, D). The patient tolerated the procedure without complications.
\end{abstract}

M. M. Smith, MD $(\bowtie) \cdot$ A. W. Amundson, MD

Department of Anesthesiology and Perioperative Medicine,

Mayo Clinic College of Medicine and Science, Rochester,

NY, USA

e-mail: Smith.Mark2@mayo.edu

T. Murray, MD

Department of Anesthesiology and Perioperative Medicine, Mayo Clinic Health System, Mankato, MN, USA

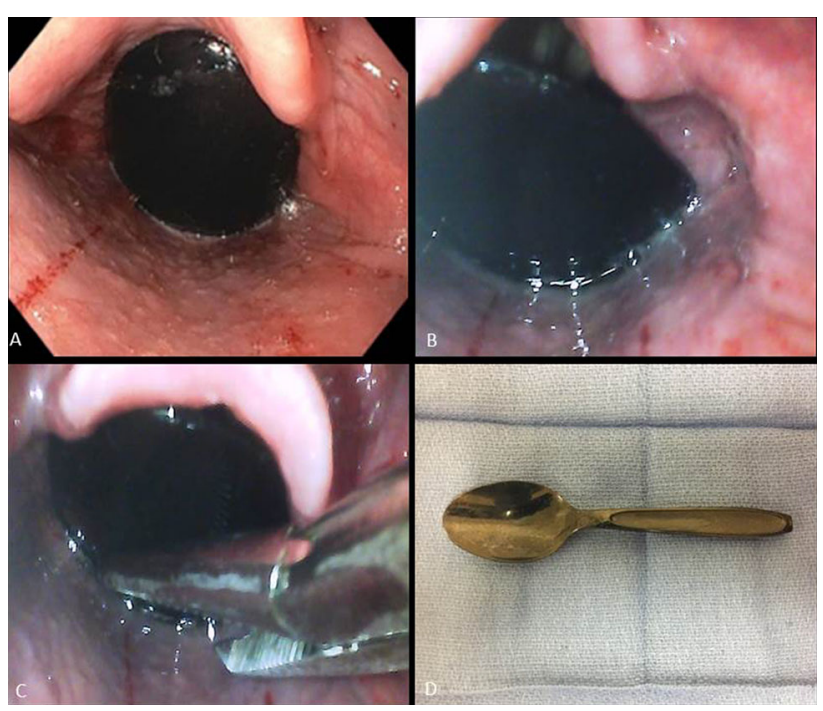

Figure This image (A) obtained during esophagogastroduodenoscopy shows the spoon lodged in the proximal esophagus. The view (B) obtained using a GlideScope ${ }^{\circledR}$ reveals the proximity of the spoon to the glottis, which was intermittently obstructed by the object. Under GlideScope ${ }^{\circledR}$ guidance, bronchoscopic forceps (C) retrieved the spoon (D)

Video laryngoscope-assisted foreign body retrieval although described in only a limited number of clinical case reports - provides clinicians with a potential alternative to flexible or rigid bronchoscopic foreign body retrieval in select cases.

Disclosure statement All authors agree with and take responsibility for the report presented. We have no financial, conflicts of interest, or personal relationships with other people or organizations to disclose.

Editorial responsibility This submission was handled by Dr. Hilary P. Grocott, Editor-in-Chief, Canadian Journal of Anesthesia. 